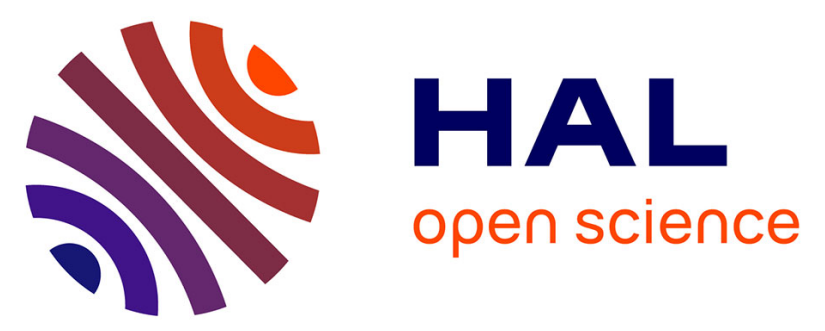

\title{
Security and safety integrated approach for multimodal-hubs crisis management: a railway and airway proposition
}

Simon Collart-Dutilleul, Hela Kadri, Philippe Bon, Georges Mykoniatis, Samir Ben Ahmed

\section{To cite this version:}

Simon Collart-Dutilleul, Hela Kadri, Philippe Bon, Georges Mykoniatis, Samir Ben Ahmed. Security and safety integrated approach for multimodal-hubs crisis management: a railway and airway proposition. TRA2020, 8th Transport Research Arena: Rethinking transport - towards clean and inclusive mobility, Apr 2020, Helsinki, Finland. hal-02952135

\section{HAL Id: hal-02952135 \\ https://hal-enac.archives-ouvertes.fr/hal-02952135}

Submitted on 29 Sep 2020

HAL is a multi-disciplinary open access archive for the deposit and dissemination of scientific research documents, whether they are published or not. The documents may come from teaching and research institutions in France or abroad, or from public or private research centers.
L'archive ouverte pluridisciplinaire HAL, est destinée au dépôt et à la diffusion de documents scientifiques de niveau recherche, publiés ou non, émanant des établissements d'enseignement et de recherche français ou étrangers, des laboratoires publics ou privés. 


\title{
Rethinking transport
}

\section{7-30 April 2020}

\section{Security and safety integrated approach for multimodal-hubs crisis management: a railway and airway proposition}

\author{
Simon Collart-Dutilleul**, Hela Kadria ${ }^{a}$, Philippe Bon ${ }^{\mathrm{a}}$, Georges Mykoniatis ${ }^{\mathrm{b}}$ and \\ Samir Ben Ahmed ${ }^{\mathrm{c}}$
}

\author{
'Ifsttar, 20 rue Elisée reclus, 59666 villeneuve d'ascq Cedex, Address, France \\ ${ }^{b}$ Enac,Avenue Edouard Belin, 31055 Toulouse cedex 4, France \\ ${ }^{c}$ Universite de Tunis El Manar, Campus Universitaire Farhat Hached, Tunisia
}

\begin{abstract}
This paper proposes a methodology to address the problem of international multi modal hubs crisis management. The analysis starts from the case study of the Brussel airport terrorist attacks to highlight multi-modal and international aspects of this kind of crisis. Then, focusing on railway and airway modes, the contextual and organizational diversity is explained. The need of a global crisis management system is justified, but the challenges ensuing from the different transportation modes are highlighted. The proposition of a modelling approach based on System of Systems formalism is studied. The possibility of building a correct by construction design of common functioning mode is justified using the scientific state of the art of formal methods providing a scientific framework for future technological and organizational innovations assessment.
\end{abstract}

Keywords: Crisis management, Safety and security integration, Multimodal approach, System of Systems, Airport, Railway,

\section{Introduction}

Each transportation mode has its own danger. Train has to avoid collisions but can stop. Airplanes cannot consider immobilization as a safe state, whereas they may easily change their route.

Considering that multi modal hubs physically connect different natures of transport infrastructures, it looks consistent to consider the global safety and security problems in a system analysis. In this case, two particular parameters need to be studied:

- The first one is the interconnection of systems where typical passenger flows are not homogeneous

- The second one is a partial alignment of safety mode specific procedures in order to allow a global defense strategy.

This paper proposes a methodology to address the problem of international multi modal hubs crisis management. A second section starts from the case study of the Brussel airport terrorist attacks to highlight multi-modal and international aspects of this kind of crisis. Then, focusing on railway and airway modes, the contextual

\footnotetext{
* Corresponding author. Tel.: +33 3-20-43-83-20;

E-mail address: Simon.Collart-Dutilleul@ifsttar.fr
} 
and organizational diversity is explained. The need of a global system crisis management is justified, and challenges ensuing from the different transportation modes are highlighted.

A third section proposes a strategy for a global multi-mode management. The System of System modelling approach is presented with its ability to embed and hide the diversity of subsystems. The next step is a correct by construction common functioning mode specification, using formal methods like B method, which provides refinements mechanisms.

The last section discusses limits and potential challenges introduced by the proposed approach.

\section{International multi modal crisis management}

\subsection{The Brussel airport case study}

\subsubsection{Presentation}

With more than 25 million passengers in 2018, The Brussels Airport is the 24th busiest airport in Europe.

In the Brussels Airport, all the facilities are located under a single roof. The terminal building has several levels:

- The railway station is located on -1 (providing national and international connections),

- buses and taxis arrive at 0 ,

- arrivals are located on level 2

- departures are on level 3.

by car, the Brussels Airport is connected to the Brussels Ring Road via the A201.

On 22 March 2016, two explosions took place in the Brussel Airport at 07:58 local time. One occurred near the American Airlines and Brussels Airlines check-in desks and the other next to a Starbucks coffee shop (as explained by Clarke and authors in the Guardian edition of 22th march 2016).

About an hour later another explosion occurred in the middle carriage of a three-carriage train at Maalbeek metro station.

\subsubsection{First analysis}

The attack of the Brussel airport is a multi-impact coordinated attack: 3 explosions in a short timeframe.

Two transport modes are directly impacted: two explosions near check-in queues in the airport and one explosion in a nearby metro station.

One may consider that the global system of transport of Brussels has been attacked. This leads to analyze the global defense strategy at the level of the global system.

Moreover, this attack is correlated with other two previous ones having occurred in France.

On August 21, 2015, a man opened fire on a Thalys train on its way from Amsterdam to Paris (see Thalys internal report of September 2015). This man entered the Thalys train in the "Brussel midi" railway station.

The November 2015 Paris attacks were a series of co-ordinated terrorist attacks that took place on November 13, 2015 in Paris.

There is clearly an international dimension to this phenomenon. Without going into details related to the international context, the perpetrators of these attacks belong more or less to the same terrorist cell.

A report of the US department of security written in July 2018 points that Complex Coordinated Terrorist Attacks (CCTAs) may among others:

- "Deploy diversions to slow public safety response, consume responder resources, or draw/reorient responders toward or away from specific locations"

- "Conduct secondary attacks on first responders, evacuation routes, and/or additional sites, such as medical facilities, that are part of the response."

Consequently CCTAs notably reveal the challenge of proposing: 
-"Operational Coordination. The complexity of these attacks requires responders to counter with a fully integrated and coordinated response."

This operational coordination is a challenge in an international context where different laws and organization structures lead to complex orchestration problems. Moreover, various transport modes have their own way of implementing a specific defense strategy because of specific danger, impacts and weaknesses.

This aspect is developed in the following, focusing on airplane and railway transport modes.

\subsection{Railway point of view}

The International Union of railways (UIC) defines a crisis as a "[...] sudden event or set of circumstances that could significantly affect an organization's ability to carry out its business [...]" (UIC (2017)) or events that could negatively impact an organization's reputation, have harmful consequences for the environment or the general public. Crisis management generally refers to the "development and application of the organizational capability to deal with [...]" (BSI (2014)) - most desirably limit - the negative outcomes of such sudden events. Usually the respective strategies and actions include preparing for possible future events as well as dealing with unforeseen incidents and are documented in a crisis management plan (CMP). The CMP can be considered "[...] a superordinate document [that] provides overall organizational and general procedural guidelines for the management of information, activities, operations and communications during an [...] emergency." (UIC (2017)) Oftentimes, in the event of crises, a special organizational structure is required to deal with all resulting challenges in an appropriate and effective manner. The crisis management team (CMT) is often part of this structure. (UIC (2017), BSI (2014))

\subsection{Airway point of view}

Coming from the history and the nature of this transport mode, the airway is more integrated at a European level: EUROCONTROL is a pan-European, civil-military organisation dedicated to supporting European aviation. Eurocontrol is the technical organization, which, at continental European level, coordinates activities of the states to achieve a set of objectives. It proposes various kinds of services including training courses for staff people. Several major works were organized at a European level related to crisis management.

Let us talk about EACCC18†. This event took place the 13th and 14th of March 2018 in Brussels. It involved 80 participants from 17 participating States. The object of the experiment was "Simulating a network crisis resulting from a pan-European cyber-attack affecting radar processing systems".

Focusing on the communication issue, let us point some of the critical points that were identified:

"different approaches from the participating States and a high risk of overreaction"

"need for harmonized and coordinated approach"

The results of the workshop for this exercise provided a particular topic focusing on "Communication structures for a crisis".

Some interesting recommendations during the crisis should be highlighted:

-"Keep your staff informed and aligned with messages"

-"Coordinate information with partner organisations"

All these works and lessons learned by the airways provide difficult objectives considering multi modal hubs, because of various management structures, because of various ways of communicating, because of different operational languages.

\subsection{Crisis management and transportation systems}

Challenges that crisis management typically faces are high levels of uncertainty, limited time, limited information and limited resources. In border areas or when inter-organizational cooperation is required, these challenges are

†http://www.eunadics.eu/sites/default/files/2018-08/3.1_EUNADICS-AV_MTMrome_presentation_Sivcev_EUROCONTROL\%20Network\%20Manager\%20enhancing\%20preparedness\%20in $\% 20$ Europe.pdf 
amplified. According to Papatheodorou, who analyzed past EU activities towards natural disaster mitigation, among others, the lack of capacity and resources for cooperation, limited knowledge about cooperating organizations and differences in organizational structures and procedures are recurring issues in cross-border cooperation (cf. Papatheodorou et al. (2014)). These problems have to be resolved because, due to a changing threat landscape, transboundary cooperation is increasingly important for crisis management (Boin et al. (2014), Surminski et al. (2017)).

Crisis management is established in all kinds of organizations. In some areas, crisis management is of more significant importance because of the large impact of potentially negative incidents, also on third parties like the environment, other businesses or the public at large. Critical infrastructure (CI) is one example for such an area. The Federal Ministry of the Interior of Germany (2009) defines CI as infrastructure that is so substantial for the well-being of society that in the case of a breakdown, "[...] sustained supply shortages, significant disruption of public safety and security, or other dramatic consequences." could occur. One example for CI is public transportation (PT)

Because of their high relevance for the society as well as the high complexity of its network, multi modal transportation hubs should be prepared for crisis so that basic functions of the infrastructure are upheld, respectively re-established as quickly as possible. Actually, theses connection nodes may transmit disturbances to all their connected networks, amplifying the overall crisis impact.

Thus, organizations within the sector of public transportation should establish their own crisis management system. Standards and guidelines are valuable tools that support the development of a crisis management structure.

Best practices suggest that crisis management systems (CMSs) cooperate with one another to deal with crises that have caused or have the potential for causing fatalities or injuries and/or major damage.

Actually, aligning knowledges of the various transport modes in a daily operational practice seems to be nontractable. Anyway focusing on information to be shared in such a way that sub-systems may cooperate to achieve a common goal looks more relevant: this modelling point of view corresponds to the System of Systems approach. This proposition is developed in the following section.

\section{Modelling approach}

\subsection{SoS structuring concept}

This cooperation leads to the concept of System-of-Systems (SoS) representing an international crisis management system. An SoS is a concept offering a high-level viewpoint encompassing the interactions between the cooperating independent systems (Jamshidi (2009)). SoS is applied in a wide range of research areas as transportation (DeLaurentis (2005)), healthcare (Wickramasinghe et al. (2008)), management (Shenhar et al. (2009), and ship environment (Mahulkar et al. (2009)).

Definition:

The United States Air Force Scientific Advisory Board defines SoSE as (United States Air Force Scientific Advisory Board, 2005):

"The process of planning, analyzing, organizing, and integrating the capabilities of a mix of existing and new systems into a system-of-systems capability that is greater than the sum of the capabilities of the constituent parts. This process emphasizes the process of discovering, developing, and implementing standards that promote interoperability among systems developed via different sponsorship, management, and primary acquisition processes."

\subsection{Common functioning mode strategy}

The railway station of Paris "Gare du Nord" deals with a bigger number of passengers than the Atlanta airport which is the biggest airport in the world (SNCF open Data 2014). Considering the same parameter, this railway station is at the 23rd rank of railway stations in the world. Considering the state of the art dealing with security, a specific approach integrating its specific aspects of passenger flows has to be considered. Control checkpoints, for example, may produce some heavy queuing phenomena generating safety problems (RSSB report, 2004).

A short analysis of the state of the art and best practices concerning overcrowding in railway provides some preliminary safety requirements (Watson et al, 2016). Those particular requirements have to be considered as soon as possible in the design phase of security protection measures. Focusing on technological solutions, it seems 
possible to control luggage and passengers without stopping people and putting luggage on conveyors (CollartDutilleul et al, 2018).

However, classical portals combined with conveyor for luggage checking are efficient in airport areas, where the passenger flow is not as high as in railway and where the danger of falling on the rail track does not exist. Even heavy congestions do not really produce specific safety problems, whereas the queuing lines may become a target for terrorist attacks.

Considering that multi modal hubs physically connect different nature of transport infrastructures, it looks consistent to consider the global safety and security problem in a system analysis. In this case two particular parameter needs to be studied:

- The first one is the global safety/security impact of interconnections of systems where typical passenger flows are not homogeneous

- The second one is to study a partial alignment of safety mode specific procedures in order to allow a global defense strategy.

Designing systems in order to integrate their connection to other ones, rather than specifying in a given environment is a wide subject. The main strategic proposition of this paper is to propose a semantic alignment in order to be able to design a set of common high-level functions enabling to express a strategy understandable by various transport modes. A high-level strategic specification

Considering European railway interoperability, some operating rules are derived from specific national laws. In the vision of a global safety and security strategy for various transport mode, laws and authorization comes from different entities. EPSF is the French railway safety agency: it is the French national safety agency for railway depending on EU Agency for Railways (ERA). The ERA sets common safety targets, common safety methods and common safety indicators, following Directive 2004/49/EC *

The railway industry is strongly linked to its own track infrastructure. As a consequence, infrastructure holders are mainly national ones. Moreover many of railway undertakers are mainly focusing on a single country.

Air safety in France and Europe also complies with the requirements of the Aviation Safety Management developed for the European Union by the EASA (the European Aviation Safety Agency).

In France, the National Supervisory Authority, DSAC monitors procedures, systems and certifies and controls the organization and content of staff training.

Air transport Area seems more centralized at a European level than railways. Actually, there is a need of single decision center for facing international crisis management.

The main proposition is to define global defense strategies defining targets and criteria (scientifically identified has common mode in SoS terminology), which are to be implemented on specific transport modes, whereas the effective interoperability efficiency has to be checked.

The high-level function defines some needed services which are used to trigger the most adapted CMP (Common Management Plan) in the UIC terminology of the railway area. At a similar architecture level a management plan

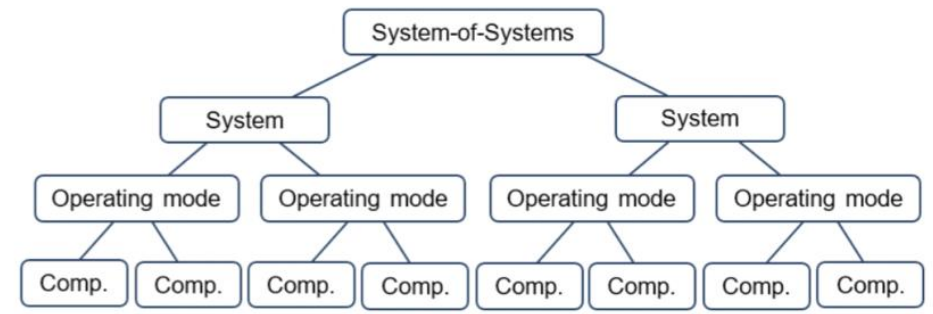

Figure 1: SoS hierarchical structure based on operating modes.

\footnotetext{
$\$$ https://eur-lex.europa.eu/legal-content/EN/ALL/?uri=celex\%3A32004L0049
} 
is defined in order to face a particular situation. The compatibility of the both plan must be carefully checked in order to define a common operating mode, able to face the situation in the global system (see figure 1).

Assuring that the correct implementation of a high level specification will be made (I.E will ensure safety or security invariant and respects the operational interoperability with other sub-systems) is a critical task.

The use of formal methods are able provide solutions as explained in the following.

\subsection{A correct by construction rule specification}

In formal methods, Specification refinement is the verifiable transformation of an abstract (high-level) formal specification into a more concrete (low-level) one.

The concept of refinement (back 1979) is the key notion for developing B models (Abrial "B Book", 1996) .

Definition: In formal methods terminology, a refinement is the verifiable transformation of an abstract (highlevel) formal specification into a more concrete (lower-level) one.

B models are accompanied by mathematical proofs that justify them. The methodology start from an abstract model and each subsequent model is a refinement of the previous one (Cansell et al, 2007 ).

The IMPEX project ${ }^{\mathrm{i}}$, addresses the problem of making explicit domain knowledge in formal system developments using refinement and proof based formal methods (Ait Ameur, et al, 2018). Refining separately different domain knowledge avoids the problem of knowledge alignment.

The PERFECT ${ }^{\text {ii }}$ project, studied a formal method based methodology for validation of railway safety rules. The proof of a safety invariant demonstrates that a corresponding global safety property is fulfilled.

Based on the state of the art, it seems possible to build a multi modal transport hub methodology, starting from a global strategy established at the level of a single decision centre and implementing it through various specific procedures which respect the high level strategy, using a correct by construction approach.

Nevertheless, the first step is a knowledge engineering problem, as basic vocabularies of various domains are not aligned. Moreover logics of operational languages are not similar. A way of dealing with this last issue is to use a system of system approach, focusing on the needed communication exchanges and building functioning modes of various sub-systems compatible between each other. The correct functioning of the global system may be assessed by checking that the corresponding accessibility graph is finite. Moreover some global or local needed properties may be assessed by the mean of theorem proving (I.E classical way of proving the correctness of a B model) or model checking technologies (like $\mathrm{ProB}^{\S}$ in the case of B models).

\section{Conclusion}

The need of an integrated global defense to face coordinated multi impact terrorist attacks targeting multi-mode transport hubs is presented using state of the art, best practices and case studies. In a second step, the proposition of a modelling approach based on SoS formalism is studied. The possibility of building a correct by construction design of common functioning mode is justified using the scientific state of the art of formal methods.

The present proposition only provides a scientific framework for future studies. Formalizing operations in diverse transportation modes requires a huge work which is only the first step before proving anything with formal methods. Moreover safety and security solutions provided by drones must be studied, whereas cyber security issues and their various impacts on the various modes is a subject of interest which cannot be avoided. Finally, considering new solutions allowed by the state of the art, for example for weapon and explosive detection, are also to be considered with their various contributions in the different transportation modes.

\footnotetext{
${ }^{\S}$ https://www3.hhu.de/stups/prob/index.php/The_ProB_Animator_and_Model_Checker
} 


\section{References}

Sean Clarke, Paul Torpey, Cath Levett, Glenn Swann, Paddy Allen, Finbarr Sheehy and Simon Jeffery "Timeline of the Brussels attacks". The Guardian. 22 March 2016.

"Internal report of Thalys" (PDF). Thalys (in French). 18 September 2015.

Report of the US Department of Homeland security: "Planning Considerations: Complex Coordinated Terrorist Attacks" July 2018

Papatheodorou, K., Klimis, N., Margaris, B., Ntouros, K., Evangelidis, K., Konstantinidis, A., 2014. "An overview of the EU actions towards natural hazard prevention and management: current status and future trends “. Journal of Environmental Protection and Ecology 15 (2), pp. $433-444$

Papatheodorou, K., Klimis, N., Margaris, B., Ntouros, K., Evangelidis, K., Konstantinidis, A., 2014. “An overview of the EU actions towards natural hazard prevention and management: current status and future trends “. Journal of Environmental Protection and Ecology 15 (2), pp. $433-444$.

Boin, A., Rhinhard, M., Ekengren, M. (2014): Managing transboundary crises: The emergence of European Union capacity. Journal of Contingencies and Crisis Management 22 (3), pp. $131-142$.

Surminski, S., Aerts, J., Alexander, D., Di Bucci, D., Mechler, R., Mysiak, J., Wilkinson, E., 2017. "Prevention and mitigation: avoiding and reducing the new and existing risks”. In: Poljansek, K., Marin Ferrer, M., De Groeve, T., Clark, I. (Eds.): Science for disaster risk management 2017: knowing better and losing less. Luxemburg: Publications Office of the European Union, pp. 449 - 464.

International Organization for Standardization (2017): ISO 22316:2017. Security and resilience. Organizational resilience. Principles and attributes. Geneva: n.a.

UIC-Security Division (eds.) (2017): Recommendations for Crisis Management. Paris: International Union of Railways (UIC).

British Standards Institution (2014): BS 11200:2014. Crisis management. Guidance and good practice. London: BSI Standards Limited.

Federal Ministry of the Interior of Germany (2009): National Strategy for Critical Infrastructure Protection. Berlin: n.a.

Jamshidi M. Systems of Systems Engineering: Principles and Applications. CRC Press, Taylor \& Francis Group, 2009.

Wickramasinghe N, Chalasan iS, Boppana R. V, and Madni A. M. Healthcare System of Systems. System of Systems Engineering Innovations for the 21st Century, (M. Jamshidi, Ed.), John Wiley Series on Systems Engineering, New York, 2008.

Shenhar A.J., and B. Sauser. Systems Engineering Management: The Multidisciplinary Discipline. In Handbook of Systems Engineering and Management, second edition, Edited by: A.P. Sage, and W.B. Rouse, John Wiley \& Sons, pages 117-154, 2009.

Mahulkar V., S. McKay, D.E. Adams, and A.R. Chaturvedi.System-ofsystems modeling and simulation of a ship environment with wireless and intelligent maintenance technologies. IEEE Transactions on Systems, Man, and Cybernetics-Part A: Systems and Humans, 39(6),pages 1255-1270, 2009.

United States Air Force Scientific Advisory Board, Report on System-of-Systems Engineering for Air Force Capability Development, Executive Summary and Annotated Brief, SAB-TR-05-04, July 2005.

"SNCF Open Data — Fréquentation en gares en 2014 “, https://ressources.data.sncf.com/explore/dataset/frequentationgares/table/?q=Paris\&sort=voyageurs_2014

RSSB, Crowd management at station- a good practice guide, (T605 Good practice guide), Railway Safety \& Standard Board, Oct 2004, https://www.rssb.co.uk/pb009693, pp. 14

Stephen Watson, Arthur D. Little, 2016, "Management of passengers at Stratford Station in London during a period of substantial growth in patronage", International Railway Safety Council, https://www.rssb.co.uk/irsc/Documents/Paris/Presentations/T10\%20Tuesday\%20-14H05-Steven-Watson.pdf, pp. 13

Simon Collart-Dutilleul, Stephan Maurer, Philippe Bon, Peter Kaul "A passenger flow oriented security and safety approach in international railway stations”, Proceedings of 7th Transport Research Arena TRA 2018, April 16-19, 2018, Vienna, Austria

Abrial, J., "The B Book - Assigning Programs to Meanings," Cambridge University Press, 1996, ISBN 0-521-49619-5.

Back, R. J. R.,On correct refinement of programs, Journal of Computer and System Sciences 23 (1979),pp. 49-68.

Cansell Dominique, Paul Gibson, Dominique Méry "Refinement: A Constructive Approach to Formal Software Design for a Secure e-voting Interface", Electronic Notes in Theoretical Computer Science (ISSN : 1571-0661), Volume 183, 11 July 2007, Pages 39-55

Ait Ameur Yamine , Idir Ait-Sadoune , Pierre Castéran , J. Paul Gibson , Kahina Hacid , Souad Kherroubi , Dominique Méry, Linda Mohand Oussaid, Neeraj Kumar Singh, Laurent Voisin, "On the Importance of Explicit Domain Modelling in Refinement-Based Modelling Design. Experiments with Event-B”, ABZ 2018 - 6th International Conference on Abstract State Machines, Alloy, B, TLA, VDM, and Z.

${ }^{\mathrm{i}}$ https://anr.fr/Project-ANR-13-INSE-0001

${ }^{\text {ii }}$ https://trimis.ec.europa.eu/project/performing-enhanced-rail-formal-engineering-constraints-traceability 